\title{
Neuroendocrine-Metabolic Dysfunction and Sleep Disturbances in Neurodegenerative Disorders: Focus on Alzheimer's Disease and Melatonin
}

\author{
Eduardo Spinedi ${ }^{a}$ Daniel P. Cardinali ${ }^{b}$ \\ ${ }^{a}$ Centre of Experimental and Applied Endocrinology (UNLP-CONICET-FCM), La Plata Medical School, La Plata National \\ University, La Plata, Argentina; ${ }^{\mathrm{b}} \mathrm{BIOMED-UCA-CONICET}$ and Department of Teaching and Research, Faculty of Medical \\ Sciences, Pontificia Universidad Católica Argentina, Buenos Aires, Argentina
}

\section{Keywords}

Alzheimer's disease $\cdot$ Feeding behavior $\cdot$ Sleep $\cdot$ Glymphatic system $\cdot$ Melatonin $\cdot$ Inflammation $\cdot$ Insulin signaling $\cdot$ Aging

\begin{abstract}
Alzheimer's disease (AD) is associated with altered eating behavior and metabolic disruption. Amyloid plaques and neurofilament tangles are observed in many hypothalamic nuclei from AD brains. Some of these areas (suprachiasmatic nuclei, lateral hypothalamic area) also play a role in the regulation of the sleep/wake cycle and may explain the comorbidity of eating and sleep disorders observed in AD patients. Inadequate sleep increases the neurodegenerative process, for example, the decrease of slow-wave sleep impairs clearance of $\beta$-amyloid peptide $(A \beta)$ and tau protein from cerebral interstitial fluid. Cerebrospinal fluid (CSF) melatonin levels decrease even in preclinical stages (Braak-1 stage) when patients manifest no cognitive impairment, suggesting that reduction of melatonin in CSF may be an early marker (the cause for which is still unknown) of oncoming AD. Melatonin administration augments glymphatic clearance of $A \beta$ and reduces generation and deposition of $A \beta$ in transgenic animal models of $A D$. It may also set up a new equilibrium
\end{abstract}

\section{KARGER}

() 2018 S. Karger AG, Basel

E-Mail karger@karger.com

www.karger.com/nen among hypothalamic feeding signals. While melatonin trials performed in the clinical phase of AD have failed to show or showed only modest positive effects on cognition, in the preclinical stage of dementia (minimal cognitive impairment) the effect of melatonin is demonstrable with significant improvement of sleep and quality of life. In this review, we discuss the main aspects of hypothalamic alterations in $A D$, the association between interrupted sleep and neurodegeneration, and the possible therapeutic effect of melatonin on these processes.

(c) 2018 S. Karger AG, Basel

\section{Introduction}

Neurodegenerative diseases are disorders characterized by progressive deterioration of brain structure and function. Degeneration of selective neuron populations gives rise to prominently cognitive symptoms in Alzheimer's disease (AD) and frontotemporal dementia or to predominantly motor symptoms in Parkinson's disease, amyotrophic lateral sclerosis, or Huntington's dis-

Both authors contributed equally to this work. 
ease. Aside from the habitual existence of neuron loss and brain inflammation, neurodegenerative disorders are also associated with altered eating behavior (hyporexia/ anorexia) and metabolic changes such as weight loss (hypoleptinemia), suggesting the participation of hypothalamic neuroendocrine areas involved in feeding behavior. Approximately $50-60 \%$ of $\mathrm{AD}$ patients manifest eating disturbances [1] and 14-80\% show poor nutritional status [2], weight loss being a clinical feature in $20-45 \%$ of $\mathrm{AD}$ cases [3].

The main symptoms of AD are memory loss associated with language deficiency, personality disorders, and alterations in sensory-motor association functions [4]. The most common form of $\mathrm{AD}$ is late onset $\mathrm{AD}$, a multifactorial, heterogeneous disorder associated with genetic factors and environmental risk factors, whereas familial forms of $\mathrm{AD}$ (accounting for less than 2-3\% of cases) are related to genetic mutations of the amyloid precursor proteins, presenilin 1 and presenilin 2. From a neuropathological perspective, AD is defined by extracellular accumulation of $\beta$-amyloid peptide $(A \beta)$ in amyloid plaques and the presence of neurofilament tangles formed by fibrillar aggregates of hyperphosphorylated tau proteins $[5,6]$. The amounts of $A \beta$ and tau in brain tissue depend on clearance mechanisms related to slow-wave sleep [7]. In this review, we briefly discuss the main aspects of hypothalamic alterations in $\mathrm{AD}$, the association between interrupted sleep and neurodegeneration, and the possible therapeutic effect of melatonin on these processes.

\section{Main Neuroendocrine-Metabolic Dysfunction in AD}

The hypothalamus is a key brain structure involved in 2 major pathways that mediate eating behavior: an appetite-stimulating pathway (orexigenic via), and an appetite-suppressing pathway (anorexigenic via) [8]. Neurons located in the hypothalamic arcuate nucleus (ARC) synthesize the orexigenic peptides neuropeptide Y (NPY) and agouti-gene related peptide (AgRP). Their axons form synapses with second-order neurons located in the lateral hypothalamic area (LHA), these cells containing the main orexigenic peptides orexin and melanin-concentrating hormone. The ARC also contains neurons encoding satiety that produce anorexigenic peptides derived from proopiomelanocortin (POMC), which co-exist with cocaine- and amphetamine-regulated transcript-containing neurons. These anorexigenic neurons project to neurons in the hypothalamic paraventricular nucleus and increase

Neuroendocrine-Metabolic Dysfunction

and Sleep Disturbances in $\mathrm{AD}$ the synthesis of corticotrophin releasing hormone, another powerful anorexigenic peptide.

Peripheral signals interact at the hypothalamic level via receptor-mediated processes to either stimulate or inhibit the orexigenic/anorexigenic pathway. For instance, enhanced circulating levels of white adipose tissue-derived leptin and pancreatic $\beta$ cell-derived insulin, as well as some gut-derived peptides (e.g., cholecystokinin, glucagon-like peptide 1, peptide YY) inhibit the hypothalamic orexigenic pathway. Conversely, stomach-derived Ghrelin, the only gut-derived orexigenic hormone, closes a feedback mechanism with hypothalamic orexigenic neurons [8]. This mechanism underlies the complexity of individual eating behavior; indeed, most hypothalamic alterations result in undesirable metabolic consequences (Fig. 1).

Several studies support significant hypothalamic atrophy in $\mathrm{AD}$ patients [9]. Amyloid plaques and neurofilament tangles are observed in many hypothalamic nuclei from $\mathrm{AD}$ brains including paraventricular nucleus, LHA, and tuberomammillary, supraoptic, and suprachiasmatic nuclei (SCN) [10] (Fig. 1). Some of these areas (SCN, LHA) play a role in the regulation of the sleep-wake cycle and may explain the comorbidity of eating and sleep disorders seen in $\mathrm{AD}$ patients. Adrenal, thyroid, and gonadal secretion are also dysfunctional in $\mathrm{AD}$ patients, dysfunctions that have been claimed to participate in $\mathrm{AD}$ physiopathology [10].

However, in $\mathrm{AD}$ patients, a dysfunctional hypothalamus induces energy homeostasis derangements and consequent dysmetabolism [11]. Among the altered metabolic pathways, obesity (body mass index higher than 30), insulin resistance (IR; a defective, downstream insulin receptor, insulin-signaling system), type 2 diabetes (fasting glycemia equal to/higher than $7 \mathrm{mM}$ and/or impaired glucose tolerance) and virus infection [12] enhance the risk of $\mathrm{AD}$ development [13]. Weight loss in AD patients appears to be associated with both amyloid burden and disease progression [3]. Importantly, weight loss precedes, by approximately 10 years, onset of $\mathrm{AD}$ symptomatology [14]. The consensus is that hypothalamic plaques and tangles are present at the early-moderate stage in $\mathrm{AD}$ and that weight loss often occurs prior to cognitive derangements. Furthermore, a body mass index decline in older age could indicate a high risk of $\mathrm{AD}$ development and a higher rate of $\mathrm{AD}$ progression [3].

Although dysmetabolism seems to be related to hypothalamic dysfunction, the signaling pathways involved are not fully understood. A number of factors other than tau and $A \beta$ hypothalamic accumulation could contribute 


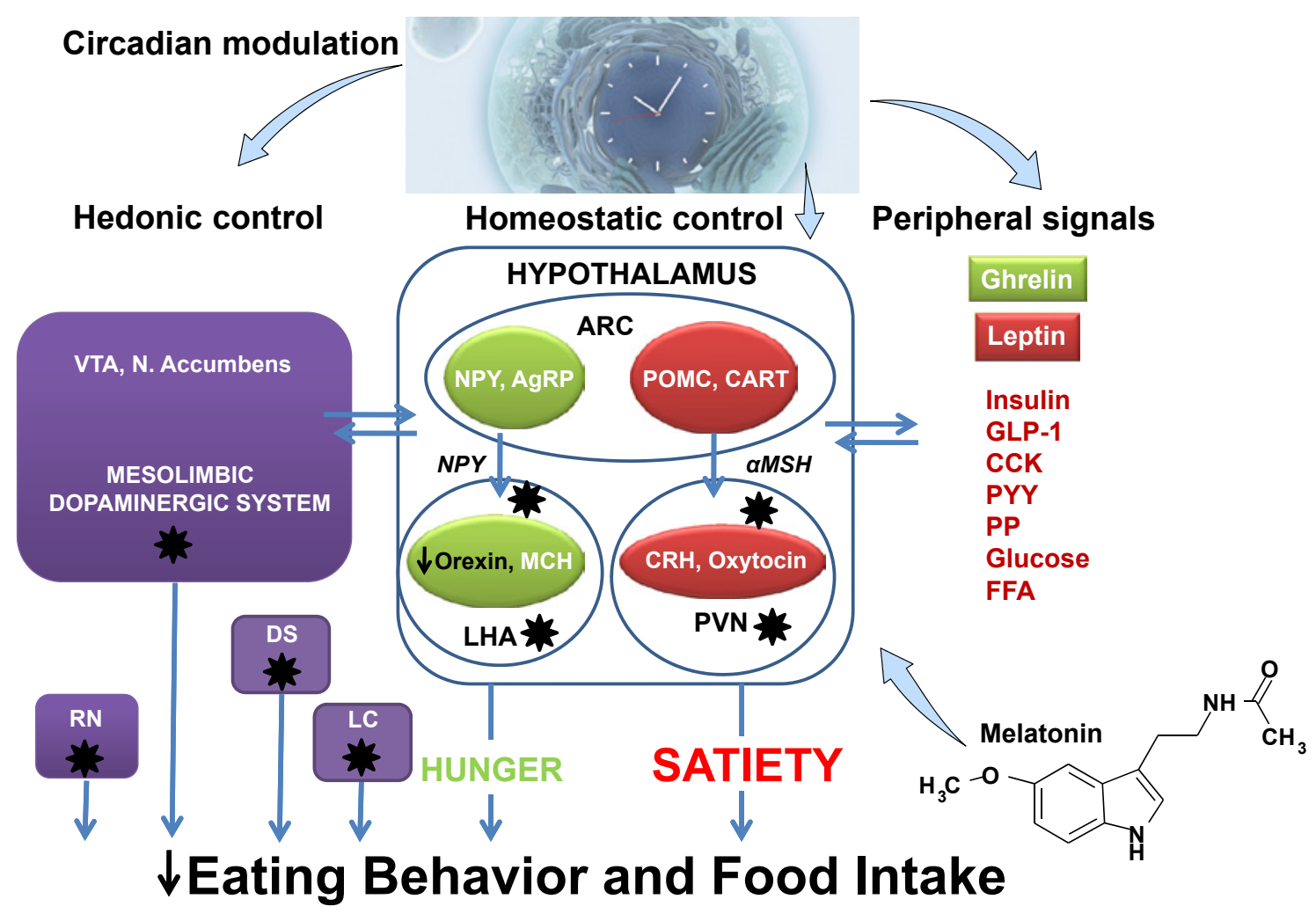

Fig. 1. Possible factors implicated in eating behavior and food intake in AD. Eating behavior is regulated by hedonic, homeostatic and peripheral signals. This scheme represents the main mechanisms, which are disturbed in AD (stars) and may affect eating behavior. The possible role of melatonin on feeding behavior is discussed in the text. VTA, ventral-tegmental area; ARC, arcuate nucleus; DS, dorsal striatum; RN, raphe nuclei; LC, locus coeru-

to dysmetabolism in AD patients. Studies support the involvement of leptin-signaling in energy homeostasis changes in $\mathrm{AD}$ [10], for example, $\mathrm{A} \beta$ peptide alters ARC NPY neuron response to leptin [15]. Indeed, although not altered, ARC leptin-receptor (leptin-R) gene expression was noticed in transgenic $\mathrm{AD}$ mice, the hypoleptinemia characterizing individuals coexists with decreased ARC POMC and cocaine- and amphetamine-regulated transcript mRNA levels, thus indicating a normal function of the anorexigenic pathway; conversely, ARC NPY and AgRP genes expressions are similar in wild-type and $\mathrm{AD}$ mice, thus indicating that dysfunctional ARC is limited to NPY-AgRP neurons [15]. This fact was similarly noticed after fasting AD mice and strongly supported by electrophysiological studies [15]. leus; PVN, paraventricular nucleus; LHA, lateral hypothalamic area; AgRP, agouti-gene related peptide; NPY, neuropeptide Y; $\mathrm{MCH}$, melanin-concentration hormone; POMC, proopiomelanocortin; CART, cocaine- and amphetamine-regulated transcript; $\mathrm{CRH}$, corticotropin-releasing hormone; GLP-1, glucagon-like peptide-1; CCK, cholecystokinin; PP, pancreatic polypeptide; PYY, peptide YY; FFA, free fatty acids.

Specifically, ARC lesion favors AD-like lesion development in different experimental models of $\mathrm{AD}[16,17]$. Weight loss in $\mathrm{AD}$ patients could also result from defective sensory (e.g., taste/olfaction) integration or processing [18].

Compelling evidence supports an interrelationship between modified glucose homeostasis and AD physiopathology, obesity, IR, and diabetes being strong risk factors for $\mathrm{AD}[13,19]$. Obesity and IR development worsen amyloidogenesis or tau pathology in $\mathrm{AD}$ transgenic models [20-22] (Fig. 2). Several studies indicate that brain IR can be enough to promote tau pathology and amyloidogenesis [23]. Interestingly, increased risk of developing diabetes has been reported in $\mathrm{AD}$ patients [24], thus supporting the interrelationship between brain lesions and 


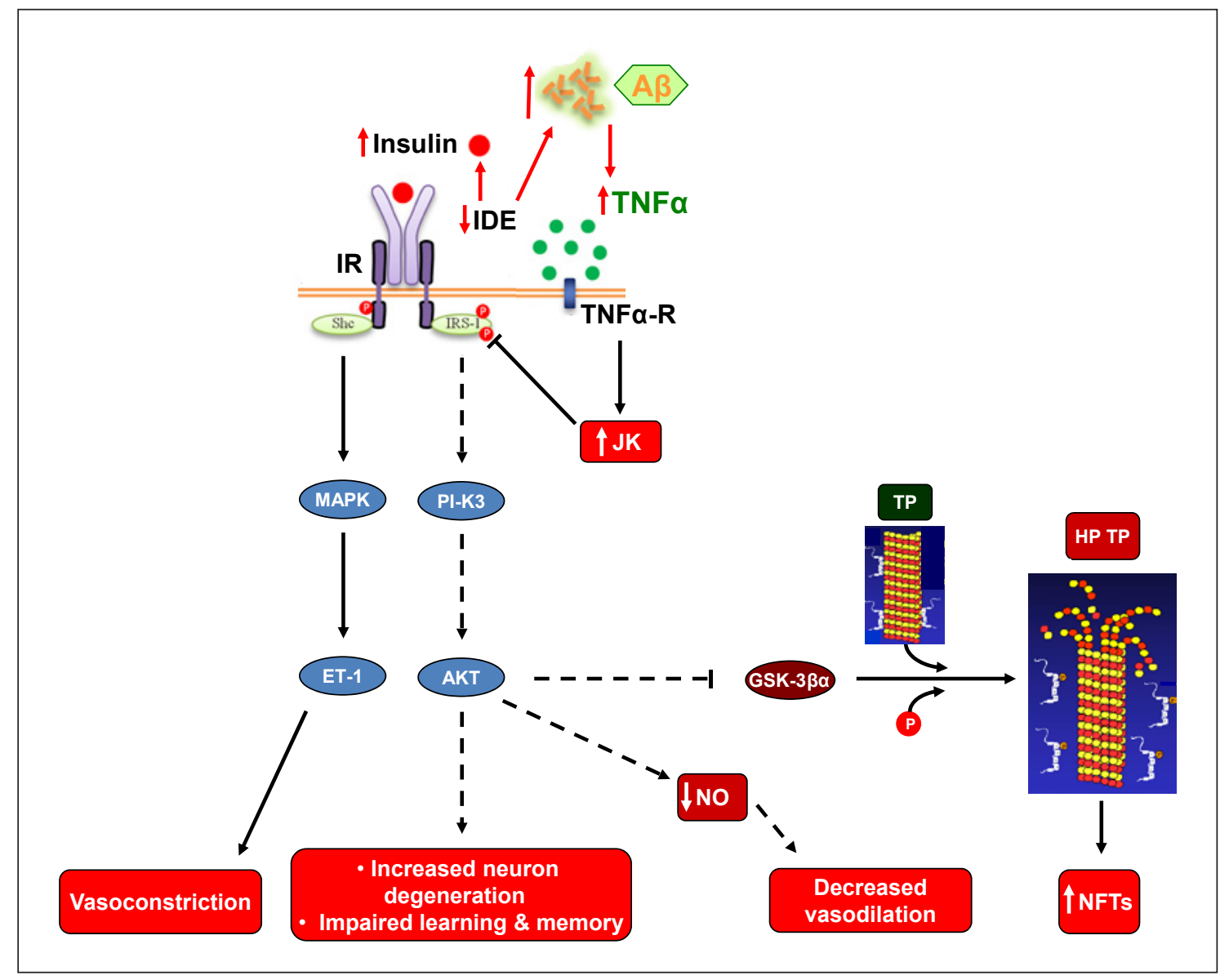

Fig. 2. Disrupted brain insulin-signaling in $A D$. Amyloid- $\beta(A \beta)$ accumulation enhances tumor necrosis factor-alpha (TNFa) levels and activates c-Jun N-terminal kinase (JNK). As a consequence, serine phosphorylation of insulin substrate receptor-1 (IRS-1) is inhibited. Insulin resistance decreases insulin degrading enzyme (IDE) expression, thus diminishing IDE-induced $\mathrm{A} \beta$ degradation. Moreover, reduced brain insulin signaling decreases the inhibition

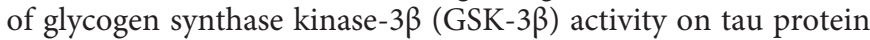

metabolic disturbances in $\mathrm{AD}$. The $\mathrm{AD}$ brain has been claimed as IR, a state correlating with the individual's cognitive score [25]. This observation is in line with the known ability of insulin signaling to promote plasticity and memory that may be relevant for changes in the cerebral cortex or the improved memory observed in humans treated with intranasal insulin [26].

The potential involvement of brain IR in impaired glucose homeostasis development in $\mathrm{AD}$ patients is also supported by the known role of insulin signaling in energy metabolism regulation [27]. The origin of IR in the AD brain seems to be related to both $A \beta$ and tau pathologies [28]. The intracerebroventricular infusion of $A \beta$ oligo-
(TP) phosphorylation resulting in hyperphosphorylated TP (PP$\mathrm{TP})$ production and microtubule depolymerization (MTDP), resulting in augmented neurofilament tangles (NFTs) deposition. Therefore, impaired insulin signaling results in neuron degeneration and modifies learning and memory. Additionally, IRS-1 deficiency reduces nitric oxide (NO) production and augmented endothelin-1 production, thus decreasing brain blood flow and increasing neuroinflammation. mers in mice triggers a pre-diabetic state (impaired glucose tolerance) by a hypothalamic-based mechanism [28], and loss of function of tau impairs insulin responsiveness and is associated with altered glucose homeostasis [29]. This is in line with increased brain insulin receptor substrate-1 (IRS-1) inhibition in patients with pure taupathies [30]. Although the underlying mechanisms remain unclear, $A \beta$ oligomers have been shown to promote insulin receptor internalization [31] as well as activation of c-Jun N-terminal kinase, Protein kinase $\mathrm{R}$, and tumor necrosis factor- $\alpha$ (TNF- $\alpha$ ) pathways, in turn resulting in IRS-1 function inhibition [28, 32]. These statements are also supported by studies indicating that peripheral glu- 
cose dysmetabolism appeared hours ( $12 \mathrm{~h}$ ) later than the rapid increase $(4 \mathrm{~h})$ in hypothalamic inflammation markers observed after icv administration of $A \beta$ oligomers in mice [28], thus indicating that glucose dysmetabolism is a consequence of the central effects induced by icv administration of $A \beta$ oligomers in mice [28]. Moreover, it has also been demonstrated that $A \beta$ oligomers-induced hypothalamic inflammation in mice, characterized by enhanced brain oxidative stress and TNF- $\alpha$ can be overridden by both antioxidant treatment [28] and when functional TNF- $\alpha$ receptor is absent [33]. Moreover, recent data suggest that apolipoprotein E4 overproduction contributes to intra-endosomic trapping of insulin receptor during late-onset, diabetes-associated $\mathrm{AD}$ [34]. Collectively, the data emphasize that glucose homeostasis impairments found in $\mathrm{AD}$ patients likely result from hypothalamic damage responsible for abnormal insulin signaling (Fig. 2).

\section{Sleep Disturbances in AD}

AD neurodegeneration extends beyond cognitive function to involve key physiological processes, including eating and sleep. The processes involved could serve as biomarkers to aid in the early diagnosis of disease [35]. In the elderly, sleep efficiency decreases to approximately $80 \%$ with an increase in sleep onset latency and in percentage of time elapsed in stages N1 and N2 (light slow sleep) and of waking after sleep onset. Other age-related declines are reductions in deep slow-wave sleep (stage N3) and in rapid eye movement (REM) sleep. The electroencephalographic spectral power analysis of polysomnographic data have confirmed that the elderly have reductions in non-REM and REM sleep and a marked decrease in delta activity [36].

The incidence of sleep disorders in patients with $\mathrm{AD}$ is close to $70 \%$, and they very often arise before the onset of cognitive deterioration [37]. In relation to non-demented individuals of the same age [38], the sleep architecture of patients with $\mathrm{AD}$ indicates a quantitative reduction of both slow-wave sleep and REM and a significant degree of sleep fragmentation that decreases daytime alertness and increases napping. Approximately half of the patients with $\mathrm{AD}$ show exacerbation of neuropsychiatric symptoms in the late afternoon/early evening, with agitation, restlessness, and confusion ("sundowning") [37, 39]. Both sleep disorders and "sundowning" are among the main reasons for institutionalization of these patients [37].
The relation between sleep and neurodegenerative diseases is bidirectional [40]. Neurodegeneration is accompanied by sleep difficulties due to reduction of amplitude and phase changes of circadian rhythms such as that of melatonin secretion, as well as the disturbing influences of neurodegenerative processes on sleep. Conversely, inadequate sleep, in terms of both duration and quality, increases the neurodegenerative process and aggravates the underlying clinical picture [40].

Several studies have shown that sleep disruption is a major contributor to neuropathology. Sleep deprivation for one night [41] or interruption of non-REM sleep [42] in healthy subjects has been shown to increase levels of $A \beta_{1-42}$ and $A \beta_{1-40}$ in cerebrospinal fluid (CSF). In mice, sleep deprivation caused increases in $\mathrm{A} \beta$ peptides in brain interstitial fluid [43], and a direct relationship was established between $A \beta$ and wakefulness. Injections of orexin, the major neuropeptide related to wakefulness, led to increases in $A \beta$, whereas the orexin antagonist almorexant decreased $A \beta$ levels [43]. A significant relationship between sleep disruption and tau pathology may also occur, as shown by the impaired memory, tau metabolism, and synaptic integrity found in a sleep-deprived mouse model of $\mathrm{AD}$ [44].

The feasible link between sleep disruption and impaired $A \beta$ and tau clearance is a dysfunctional glymphatic system (Fig. 3). The glymphatic hypothesis [45, 46] holds that the movements of solutes in brain extracellular space (ECS) occur by exchange of water driven by perivascular astrocytes through aquaporin-4 (AQP4) channels and by changes in vascular lumen. AQP4 is expressed predominantly in the feet of astrocytes and the passage of water through $\mathrm{AQP} 4$ is responsible for an exchange of fluids actively driven between para-arterial and paravenous spaces via a convective flow of interstitial fluid. It has been assumed that arteriolar pulsations, as well as venular collapse dependent on respiration contribute to this convective flow [47]. Exchange of solutes between CSF and interstitial fluid occurs mainly during slow-wave sleep when the cortical interstitial space increases by over $60 \%$, providing a low resistance route for the movement of CSF and interstitial fluid in the brain parenchyma [45, 46].

The concept of $A \beta$ clearance by the glymphatic system received support from the observation that elimination of radiolabeled $A \beta$ peptide injected is strongly reduced in knockout mice for AQP4 channels [45]. In fact, the location of AQP4 in the feet of perivascular astrocytes is known to be highly altered in $\mathrm{AD}$ [48], and from this point of view, $\mathrm{AD}$ development and progression may be 
Fig. 3. Sleep disruption, particularly of slow-wave sleep, and altered feeding behavior, are frequent features in $\mathrm{AD}$. Reduced slow-wave activity impairs glymphatic amyloid- $\beta(A \beta)$ clearance, which is greatest in the sleeping brain. Metabolic demand increases with loss of slow-wave sleep, augmenting A $\beta$ formation. Astrogliosis associated with aging, small vessel disease, traumatic brain injury, or amyloid plaques is associated with impaired glymphatic pathway function, possibly via impairment of perivascular aquaporin-4 localization. The presence of $A \beta$ aggregates specifically inhibits slow-wave activity. Melatonin counteracts most of the dysfunctions observed and may improve feeding behavior signaling at the hypothalamic level.

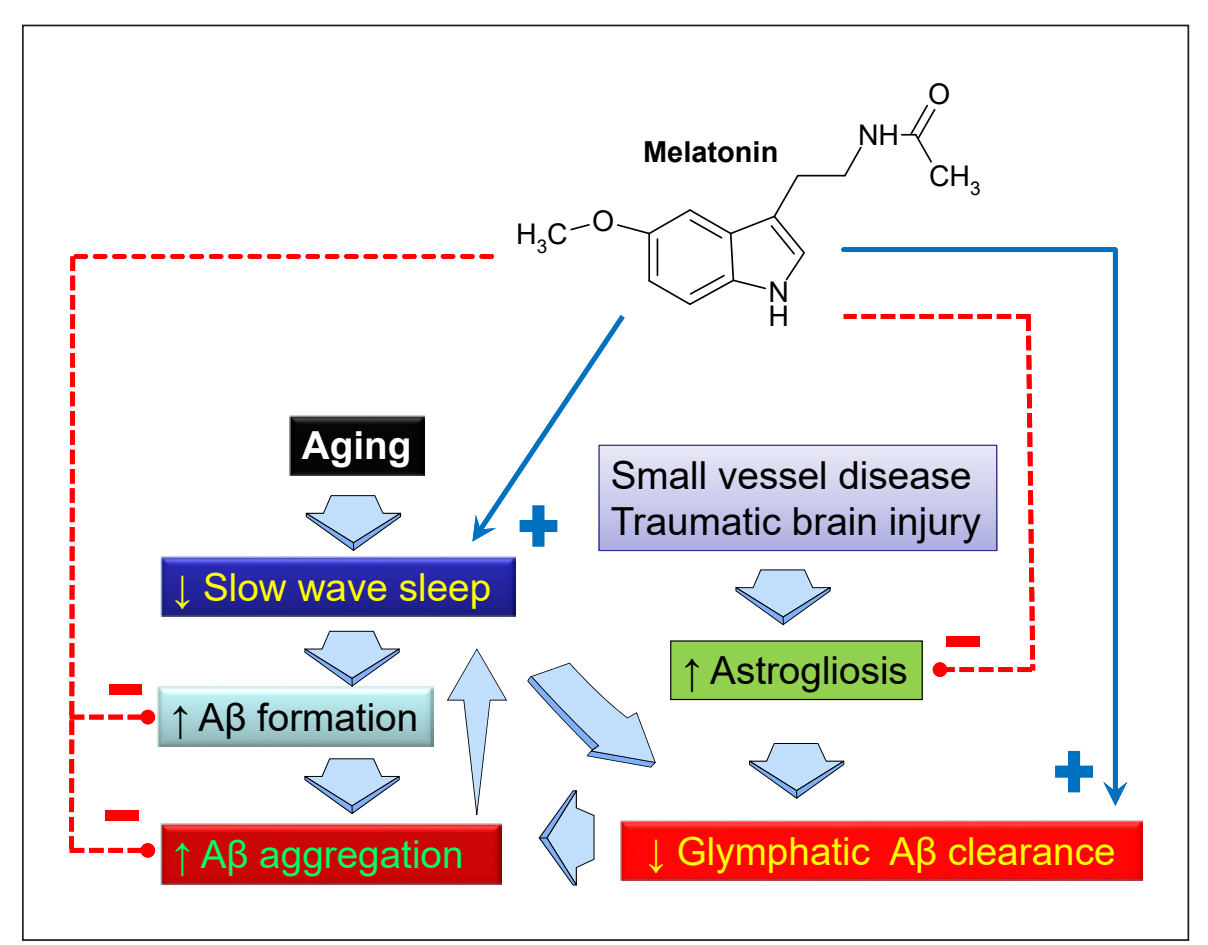

due to failure of $A \beta$ clearance, which is aggravated by sleep disturbance [49]. Another aspect related to AD refers to the clearance of apolipoprotein E from the ECS, since sleep deprivation was found to suppress this process [50] as well as elimination of tau protein from ECS [51]. Although the glymphatic hypothesis remains a matter of controversy [52], the role of normal sleep for correct cerebral clearance of toxic products can be considered well established (Fig. 3).

\section{Melatonin in AD}

Severe disruption of the circadian system occurs in $\mathrm{AD}$, indicated by alterations in numerous body rhythms, such as body temperature, plasma glucocorticoids and plasma melatonin. An emerging symptom of this circadian disruption is "sundowning," a chronobiological phenomenon observed in patients with $\mathrm{AD}$ along with sleep and wakefulness disorder. Chronotherapeutic interventions such as exposure to bright light and timed melatonin administration in selected circadian phases alleviated "sundowning" and improved sleep-wake patterns in patients with $\mathrm{AD}[53,54]$.

The pineal methoxyindole melatonin is a synchronizer of the SCN clockwork [55]. In mammals, melatonin is synthesized in the pineal gland in a rhythmic manner, with high levels during nighttime and low levels during daytime. Melatonin phase-shifts circadian rhythms in the SCN by acting on $\mathrm{MT}_{1}$ and $\mathrm{MT}_{2}$ melatonin receptors expressed in SCN neurons, thus creating a reciprocal interaction between the SCN and the pineal gland. The circadian rhythm in the secretion of melatonin has been shown to be responsible for the sleep/wake rhythm in both normal and blind subjects (i.e., in the absence of the synchronizing effect of light) [56].

Melatonin exhibits an amazing phylogenetic conservation from unicellular organisms to higher vertebrates that strongly suggests a cytoprotective function. Experimental treatment with melatonin has been demonstrated to be neuroprotective in aging and $\mathrm{AD}$ animal models, as its administration decreased the accumulation of $A \beta$ and hyperphosphorylated tau, improved neuroplasticity and neuron survival, prevented learning and memory impairment, and ameliorated anxiety and depression-like behavior (see [57, 58]).

Early work of Pappolla et al. indicated that melatonin efficiently reduces the generation and deposition of $A \beta$ [59-62] (Fig. 3). Melatonin administration also increases A $\beta$ glymphatic clearance [63]. Since melatonin inhibits only the first stages of $A \beta$ aggregation (nucleation phase) but does not revert oligomers or fibrils once they are 
formed, its therapeutic application in $\mathrm{AD}$ prevention should be considered [64]. Concerning tau, melatonin was effective to inhibit $A \beta$-induced tau protein hyperphosphorylation via PI3K/Akt/GSK3 $\beta$ signaling in murine hipoccampus [65].

The imbalance between inflammatory and anti-inflammatory signals is a hallmark of the neurodegenerative process that contributes to $\mathrm{AD}$ progression. The term "inflammaging" was introduced to underscore the importance of inflammation in senescence and its role in the development of age-related diseases [66]. Reversal of inflammation by melatonin occurs at different levels. Melatonin is effective in suppressing IR, a hallmark of the metabolic syndrome, by reversing the blockade of a key step in transduction of insulin signals, that is, reduced phosphorylation of IRS-1 [67]. Another important aspect of anti-inflammaging activity of melatonin is its role as an immunological buffer, comprising both proinflammatory and anti-inflammatory effects. In several conditions such as senescence and cancer, the anti-inflammatory aspects of melatonin prevail [68].

As for appetite regulation, the possible involvement of melatonin has been studied for years. Melatonin regulates food intake in rats [69], mice [70], hamsters [71], pigs [72], and several submammalian species such as goldfish [73], rainbow trout [74], and zebrafish [75]. In rat, conflicting responses include reduction, increase, or no effect on food consumption $[76,77]$. A decrease in fat mass and body weight has been reported in rats [77-79], whereas melatonin increases fat mass in gray mouse lemurs [80], Syrian hamster [71], raccoon dog [81], and garden dormouse [82].

In a study evaluating gene expression of NPY, leptin$\mathrm{R}, \mathrm{POMC}$, prolactin-releasing peptide (PrRP), insulin receptor, IRS-1, and IRS-2 in the medial basal hypothalamus of obese rats, we reported that treatment for 10 weeks with $2.3 \mathrm{mg} / \mathrm{kg}$ melatonin, suppressed augmented medial basal hypothalamus mRNA levels of NPY, leptin-R, PrRP, insulin-R, IRS-1, and IRS-2 [83]. These results suggested that melatonin administration might be able to set up a new equilibrium among hypothalamic feeding signals (Fig. 1,3). Remarkably, melatonin reduced gene expression of both the strong orexinergic signal NPY and the anorexinergic signal PrRP, as well as that of receptors for anorexigenic signals such as leptin and insulin, and of insulin intracellular signaling (IRS-1, IRS-2) [83]. Whether this effect is relevant for clinically demonstrated activity of melatonin in $\mathrm{AD}$ patients deserves further exploration.

Melatonin trials performed in the clinical phase of $\mathrm{AD}$ have failed to show [84] or show only modest positive ef- fects on cognition $[85,86]$. Based on preclinical data, melatonin is more likely to prevent the aggregation of $\mathrm{A} \beta$ rather than to reverse neuropathology in the clinically manifest phases of the disease. Normal aging is characterized by a decline in cognitive abilities which includes reasoning, memory, and semantic fluency, already detectable in the 5th decade of life. There is evidence of a preclinical stage in dementia in which cognitive performance is limited compared to normal aging (minimal cognitive impairment [MCI]) [87]. In community-based studies, close to $30 \%$ of a sample of older people living in the community showed performance deficits not explained by changes related to age, education level, mood, or health condition [88]. This finding strongly suggests the existence of early pathological changes: a state of transition that occurs between normal aging and early AD. Analysis of published data on melatonin administration in the early stages of cognitive decline consistently showed that melatonin, taken every night before retiring, improves quality of sleep and cognitive performance in this phase of the disease (see [89]). In MCI patients, the effect of melatonin is demonstrable, with significant improvement of sleep and quality of life and reduction of cognitive impairment [90].

CSF melatonin levels decrease even in preclinical stages of $\mathrm{AD}$ when patients manifest no cognitive impairment, suggesting that reduction in CSF melatonin may be an early trigger and marker for $\mathrm{AD}[91,92]$. Although it is not known whether the relative melatonin deficiency is a consequence or a cause of neurodegeneration, it seems clear that loss of melatonin aggravates the disease and that early circadian disruption may be an important deficit to be considered. A recent study observed significant differences in melatonin levels between $\mathrm{MCI}$ and $\mathrm{AD}$ patients, with a negative correlation between neuropsychological assessment of dementia and melatonin levels [93]. Two meta-analyses endorsed the view that melatonin therapy is effective in improving sleep in patients with dementia [94, 95]. Moreover, the melatoninergic agonist ramelteon was reported to be effective to treat delirium, an acute state of mental confusion that may lead to many adverse sequelae in intensive care unit elderly patients [96].

\section{Conclusions and Remarks}

Evidence discussed here supports a significant hypothalamic alteration in $\mathrm{AD}$ patients resulting in energy homeostasis disorders and dysmetabolism, weight loss being as- 
sociated with disease progression. In fact, obesity, IR, and type 2 diabetes are important risk factors for AD development. In addition, the incidence of sleep disorders in patients with $\mathrm{AD}$ is close to $70 \%$, about $50 \%$ of patients with $\mathrm{AD}$ showing exacerbation of neuropsychiatric symptoms in the late afternoon- early evening ("sundowning"). This disruption of the sleep-wake cycle affects normal cerebral perivascular and non-perivascular removal of toxic waste by affecting directional and nondirectional CSF flow.

Melatonin combines 2 properties for application in human medicine: chronobiotic and cytoprotection. Many published studies support a significant chronobiologic regulatory effect of melatonin on sleep. In a meta-analysis including 19 studies involving 1683 subjects, melatonin showed significant efficacy in reducing sleep latency and also increased total sleep time [97]. Trials of longer duration and the use of higher doses of melatonin demonstrated greater effects. Several consensus statements also support this role of melatonin. For example, the British Association for Psychopharmacology consensus statement on evidence-based treatment of insomnia, parasomnias, and circadian rhythm disorders concluded that "melatonin should be the choice hypnotic for insomniacs over 55 years of age" [98]. In 2007, a sustained release form of 2-mg melatonin (Circadin ${ }^{\circledR}$, Neurim, Tel-Aviv) was approved by the European Medicines Agency (EMA) for treatment of insomnia in elderly people. The fact that melatonin does not show evidence of dependency, isolation, rebound insomnia, or negative influence on alertness during the day was emphasized by the EMA and also the US Food and Drug Administration, for the melatonin analogs ramelteon (Rozerem ${ }^{\circledR}$, Takeda) and tasimelteon (Hetlioz ${ }^{\circledR}$, Vanda).

Concerning cytoprotection, almost every cell in the human body contains melatonin in quantities much higher than those circulating in blood derived from the pineal gland. To modify intracellular melatonin levels doses much higher than those utilized as a chronobiotic are required (i.e., in the $40-100 \mathrm{mg} /$ day range) [99]. In view of studies in animal models of $\mathrm{AD}$, it has become ap- parent that several potentially useful effects of melatonin such as prevention of $A \beta$ formation of tau phosphorylation require doses of melatonin in the order of $>100 \mathrm{mg} /$ day as the equivalent human dose. If we expect melatonin to be effective in improving health, especially in elderly people, it is likely that the low doses of melatonin commonly administered up to the present (under $10 \mathrm{mg} /$ day) are not beneficial. Published reports indicate that melatonin is a safe drug with low toxicity (for references see [67]). In 2 dose-escalation studies of melatonin in healthy volunteers, tolerability and pharmacokinetics of up to $100 \mathrm{mg}$ oral doses of melatonin were assessed with no adverse effects detected $[100,101]$. However, the safety of melatonin in long-term treatment remains to be settled.

Melatonin enrichment of food could offer a strategy to reach amounts providing effective cytoprotection in $\mathrm{AD}$. Therefore, one area of interest is the development of functional foods containing high levels of melatonin. Melatonin is widely used as a food supplement, dietetic product, and drug in many countries worldwide. The European Food Safety Authority has admitted the health claim that melatonin reduces sleep onset latency [102]. Melatoninrich food and bioextracts can therefore now be developed to serve as nutritional supplements, dietetic products, and drugs.

\section{Acknowledgments}

The authors wish to thank Susan H. Rogers for editing and correcting this manuscript. The authors are Research Career Awardees from the National Research Council of Argentina (CONICET). Studies carried out by the authors were supported by grant PICT (2007-01045 and 2012-0984, to DPC) from the ANPCyT, Argentina and, the Swiss Foundation for Research on Endocrinology, Diabetes and Metabolism (FPREDM052015, to ES).

\section{Disclosure Statement}

The authors declare they have no conflicts of interest to disclose.

\section{References}

Neuroendocrine-Metabolic Dysfunction and Sleep Disturbances in $\mathrm{AD}$
1 Ikeda M, Brown J, Holland AJ, Fukuhara R, Hodges JR. Changes in appetite, food preference, and eating habits in frontotemporal dementia and Alzheimer's disease. J Neurol Neurosurg Psychiatry. 2002 Oct;73(4):371-6.

2 Suma S, Watanabe Y, Hirano H, Kimura A, Edahiro A, Awata S, et al. Factors affecting the appetites of persons with Alzheimer's disease and mild cognitive impairment. Geriatr Gerontol Int. 2018 Aug;18(8):1236-43.
3 Aziz NA, van der Marck MA, Pijl H, Olde Rikkert MG, Bloem BR, Roos RA. Weight loss in neurodegenerative disorders. J Neurol. 2008 Dec;255(12):1872-80.

4 Blennow K, de Leon MJ, Zetterberg $\mathrm{H}$. Alzheimer's disease. Lancet. 2006 Jul;368(9533): 387-403.

5 Braak H, Braak E. Staging of Alzheimer's disease-related neurofibrillary changes. Neurobiol Aging. 1995 May-Jun;16(3):271-8. 
6 Braak H, Braak E. Pick's disease: cytoskeletal changes in the hypothalamic lateral tuberal nucleus. Brain Res. 1998 Aug;802(1-2):11924.

7 Tarasoff-Conway JM, Carare RO, Osorio RS, Glodzik L, Butler T, Fieremans E, et al. Clearance systems in the brain-implications for Alzheimer disease. Nat Rev Neurol. 2015 Aug; 11(8):457-70.

8 Pagano ES, Spinedi E, Gagliardino JJ. White adipose tissue and circadian rhythm dysfunctions in obesity: pathogenesis and available therapies. Neuroendocrinology. 2017;104(4): 347-63.

9 Loskutova N, Honea RA, Brooks WM, Burns JM. Reduced limbic and hypothalamic volumes correlate with bone density in early Alzheimer's disease. J Alzheimers Dis. 2010; 20(1):313-22.

10 Ishii M, Iadecola C. Metabolic and non-cognitive manifestations of Alzheimer's disease: the hypothalamus as both culprit and target of pathology. Cell Metab. 2015 Nov;22(5):76176.

11 Emmerzaal TL, Kiliaan AJ, Gustafson DR. 2003-2013: a decade of body mass index, Alzheimer's disease, and dementia. J Alzheimers Dis. 2015;43(3):739-55.

12 Harris SA, Harris EA. Herpes Simplex Virus Type 1 and Other Pathogens are Key Causative Factors in Sporadic Alzheimer's Disease. J Alzheimers Dis. 2015;48(2):319-53.

13 Profenno LA, Porsteinsson AP, Faraone SV. Meta-analysis of Alzheimer's disease risk with obesity, diabetes, and related disorders. Biol Psychiatry. 2010 Mar;67(6):505-12.

14 Müller S, Preische O, Sohrabi HR, Gräber S, Jucker M, Dietzsch J, et al. Decreased body mass index in the preclinical stage of autosomal dominant Alzheimer's disease. Sci Rep. 2017 Apr;7(1):1225.

15 Ishii M, Wang G, Racchumi G, Dyke JP, Iadecola C. Transgenic mice overexpressing amyloid precursor protein exhibit early metabolic deficits and a pathologically low leptin state associated with hypothalamic dysfunction in arcuate neuropeptide $\mathrm{Y}$ neurons. J Neurosci. 2014 Jul;34(27):9096-106.

16 Dief AE, Kamha ES, Baraka AM, Elshorbagy AK. Monosodium glutamate neurotoxicity increases beta amyloid in the rat hippocampus: a potential role for cyclic AMP protein kinase. Neurotoxicology. 2014 May;42:76-82.

17 Špolcová A, Mikulášková $\mathrm{B}$, Holubová $\mathrm{M}, \mathrm{Na}-$ gelová V, Pirnik Z, Zemenová J, et al. Anorexigenic lipopeptides ameliorate central insulin signaling and attenuate tau phosphorylation in hippocampi of mice with monosodium glutamate-induced obesity. J Alzheimers Dis. 2015;45(3):823-35.

18 Kouzuki M, Suzuki T, Nagano M, Nakamura S, Katsumata Y, Takamura A, et al. Comparison of olfactory and gustatory disorders in Alzheimer's disease. Neurol Sci. 2018 Feb; 39(2):321-8.
19 Schrijvers EM, Witteman JC, Sijbrands EJ, Hofman A, Koudstaal PJ, Breteler MM. Insulin metabolism and the risk of Alzheimer disease: the Rotterdam Study. Neurology. 2010 Nov;75(22):1982-7.

20 Kohjima M, Sun Y, Chan L. Increased food intake leads to obesity and insulin resistance in the tg2576 Alzheimer's disease mouse model. Endocrinology. 2010 Apr; 151(4): 1532-40.

21 Leboucher A, Laurent C, Fernandez-Gomez FJ, Burnouf S, Troquier L, Eddarkaoui S, et al. Detrimental effects of diet-induced obesity on $\tau$ pathology are independent of insulin resistance in $\tau$ transgenic mice. Diabetes. 2013 May;62(5):1681-8.

22 Moser VA, Pike CJ. Obesity accelerates Alzheimer-related pathology in APOE4 but not APOE3 mice. eNeuro. 2017 Jun; 4(3):ENEURO.0077-17.2017.

23 Stanley M, Macauley SL, Holtzman DM. Changes in insulin and insulin signaling in Alzheimer's disease: cause or consequence? J Exp Med. 2016 Jul;213(8):1375-85.

24 Janson J, Laedtke T, Parisi JE, O’Brien P, Petersen RC, Butler PC. Increased risk of type 2 diabetes in Alzheimer disease. Diabetes. 2004 Feb;53(2):474-81.

25 Talbot K, Wang HY, Kazi H, Han LY, Bakshi KP, Stucky A, et al. Demonstrated brain insulin resistance in Alzheimer's disease patients is associated with IGF-1 resistance, IRS-1 dysregulation, and cognitive decline. J Clin Invest. $2012 \mathrm{Apr} ; 122(4): 1316-38$.

26 Grillo CA, Piroli GG, Lawrence RC, Wrighten SA, Green AJ, Wilson SP, et al. Hippocampal insulin resistance impairs spatial learning and synaptic plasticity. Diabetes. 2015 Nov; 64(11):3927-36.

27 Steculorum SM, Solas M, Brüning JC. The paradox of neuronal insulin action and resistance in the development of aging-associated diseases. Alzheimers Dement. 2014 Feb;10(1 Suppl):S3-11.

28 Clarke JR, Lyra E Silva NM, Figueiredo CP, Frozza RL, Ledo JH, Beckman D, et al. Alzheimer-associated $A \beta$ oligomers impact the central nervous system to induce peripheral metabolic deregulation. EMBO Mol Med. 2015 Feb;7(2):190-210.

29 Marciniak E, Leboucher A, Caron E, Ahmed T, Tailleux A, Dumont J, et al. Tau deletion promotes brain insulin resistance. J Exp Med. 2017 Aug;214(8):2257-69.

30 Yarchoan M, Toledo JB, Lee EB, Arvanitakis Z, Kazi H, Han LY, et al. Abnormal serine phosphorylation of insulin receptor substrate 1 is associated with tau pathology in Alzheimer's disease and tauopathies. Acta Neuropathol. 2014 Nov;128(5):679-89.

31 Zhao WQ, De Felice FG, Fernandez S, Chen H, Lambert MP, Quon MJ, et al. Amyloid beta oligomers induce impairment of neuronal insulin receptors. FASEB J. 2008 Jan;22(1):24660.
32 Lourenco MV, Ferreira ST, De Felice FG. Neuronal stress signaling and eIF $2 \alpha$ phosphorylation as molecular links between Alzheimer's disease and diabetes. Prog Neurobiol. 2015 Jun;129:37-57.

33 Romanatto T, Roman EA, Arruda AP, Denis RG, Solon C, Milanski M, et al. Deletion of tumor necrosis factor- $\alpha$ receptor 1 (TNFR1) protects against diet-induced obesity by means of increased thermogenesis. J Biol Chem. 2016 Dec;291(52):26934.

34 Zhao N, Liu CC, Van Ingelgom AJ, Martens YA, Linares C, Knight JA, et al. Apolipoprotein $\mathrm{E} 4$ impairs neuronal insulin signaling by trapping insulin receptor in the endosomes. Neuron. 2017 Sep;96(1):115-129.e5.

35 Ahmed RM, Ke YD, Vucic S, Ittner LM, Seeley W, Hodges JR, et al. Physiological changes in neurodegeneration - mechanistic insights and clinical utility. Nat Rev Neurol. 2018 May; 14(5):259-71.

36 Chellappa SL, Münch M, Knoblauch V, Cajochen C. Age effects on spectral electroencephalogram activity prior to dream recall. J Sleep Res. 2012 Jun;21(3):247-56.

37 Peter-Derex L, Yammine P, Bastuji H, Croisile B. Sleep and Alzheimer's disease. Sleep Med Rev. 2015 Feb;19:29-38.

38 Zdanys KF, Steffens DC. Sleep disturbances in the elderly. Psychiatr Clin North Am. 2015 Dec;38(4):723-41.

39 Taylor JL, Friedman L, Sheikh J, Yesavage JA. Assessment and management of "sundowning" phenomena. Semin Clin Neuropsychiatry. 1997 Apr;2(2):113-22.

40 Mazzotti DR, Guindalini C, Moraes WA, Andersen ML, Cendoroglo MS, Ramos LR, et al. Human longevity is associated with regular sleep patterns, maintenance of slow wave sleep, and favorable lipid profile. Front Aging Neurosci. 2014 Jun;6:134.

41 Ooms S, Overeem S, Besse K, Rikkert MO, Verbeek M, Claassen JA. Effect of 1 night of total sleep deprivation on cerebrospinal fluid $\beta$-amyloid 42 in healthy middle-aged men: a randomized clinical trial. JAMA Neurol. 2014 Aug;71(8):971-7.

42 Ju YS, Ooms SJ, Sutphen C, Macauley SL, Zangrilli MA, Jerome G, et al. Slow wave sleep disruption increases cerebrospinal fluid amyloid- $\beta$ levels. Brain. 2017 Aug; 140(8): 2104-11.

43 Kang JE, Lim MM, Bateman RJ, Lee JJ, Smyth LP, Cirrito JR, et al. Amyloid-beta dynamics are regulated by orexin and the sleep-wake cycle. Science. 2009 Nov;326(5955):1005-7.

44 Di Meco A, Joshi YB, Praticò D. Sleep deprivation impairs memory, tau metabolism, and synaptic integrity of a mouse model of Alzheimer's disease with plaques and tangles. Neurobiol Aging. 2014 Aug;35(8):1813-20.

45 Iliff JJ, Wang M, Liao Y, Plogg BA, Peng W, Gundersen GA, et al. A paravascular pathway facilitates CSF flow through the brain parenchyma and the clearance of interstitial solutes, including amyloid $\beta$. Sci Transl Med. 2012 Aug;4(147):147ra111. 
46 Jessen NA, Munk AS, Lundgaard I, Nedergaard M. The glymphatic system: a beginner's guide. Neurochem Res. 2015 Dec;40(12): 2583-99.

47 Nedergaard M. Neuroscience. Garbage truck of the brain. Science. 2013 Jun;340(6140): 1529-30.

48 Zeppenfeld DM, Simon M, Haswell JD, D'Abreo D, Murchison C, Quinn JF, et al. Association of perivascular localization of aquaporin- 4 with cognition and Alzheimer disease in aging brains. JAMA Neurol. 2017 Jan; 74(1):91-9.

49 Yulug B, Hanoglu L, Kilic E. Does sleep disturbance affect the amyloid clearance mechanisms in Alzheimer's disease? Psychiatry Clin Neurosci. 2017 Oct;71(10):673-7.

50 Achariyar TM, Li B, Peng W, Verghese PB, Shi Y, McConnell E, et al. Glymphatic distribution of CSF-derived apoE into brain is isoform specific and suppressed during sleep deprivation. Mol Neurodegener. 2016 Dec 11(1):74.

51 Iliff JJ, Chen MJ, Plog BA, Zeppenfeld DM, Soltero M, Yang L, et al. Impairment of glymphatic pathway function promotes tau pathology after traumatic brain injury. J Neurosci. 2014 Dec;34(49):16180-93.

52 Smith AJ, Verkman AS. The "glymphatic" mechanism for solute clearance in Alzheimer's disease: game changer or unproven speculation? FASEB J. 2018 Feb;32(2):543-51.

53 Cardinali DP, Brusco LI, Liberczuk C, Furio AM. The use of melatonin in Alzheimer's disease. Neuro Endocrinol Lett. 2002 Apr;23 Suppl 1:20-3.

54 Riemersma-van der Lek RF, Swaab DF, Twisk J, Hol EM, Hoogendijk WJ, Van Someren EJ. Effect of bright light and melatonin on cognitive and noncognitive function in elderly residents of group care facilities: a randomized controlled trial. JAMA. 2008 Jun;299(22): 2642-55.

55 Hardeland R, Madrid JA, Tan DX, Reiter RJ. Melatonin, the circadian multioscillator system and health: the need for detailed analyses of peripheral melatonin signaling. J Pineal Res. 2012 Mar;52(2):139-66.

56 Skene DJ, Arendt J. Circadian rhythm sleep disorders in the blind and their treatment with melatonin. Sleep Med. 2007 Sep;8(6) 651-5

57 Shukla M, Govitrapong P, Boontem P, Reiter RJ, Satayavivad J. Mechanisms of Melatonin in Alleviating Alzheimer's Disease. Curr Neuropharmacol. 2017;15(7):1010-31.

58 Corpas R, Griñán-Ferré C, Palomera-Ávalos V, Porquet D, García de Frutos P, Franciscato Cozzolino SM, et al. Melatonin induces mechanisms of brain resilience against neurodegeneration. J Pineal Res. 2018 Nov;65(4): e12515.

59 Pappolla M, Bozner P, Soto C, Shao H, Robakis $\mathrm{NK}$, Zagorski $\mathrm{M}$, et al. Inhibition of $\mathrm{Al}$ zheimer beta-fibrillogenesis by melatonin. J Biol Chem. 1998 Mar;273(13):7185-8.
60 Pappolla MA, Sos M, Omar RA, Bick RJ, Hickson-Bick DL, Reiter RJ, et al. Melatonin prevents death of neuroblastoma cells exposed to the Alzheimer amyloid peptide. J Neurosci. 1997 Mar; 17(5):1683-90.

61 Pappolla MA, Chyan YJ, Poeggeler B, Bozner P, Ghiso J, LeDoux SP, et al. Alzheimer beta protein mediated oxidative damage of mitochondrial DNA: prevention by melatonin. J Pineal Res. 1999 Nov;27(4):226-9.

62 Poeggeler B, Miravalle L, Zagorski MG, Wisniewski T, Chyan YJ, Zhang Y, et al. Melatonin reverses the profibrillogenic activity of apolipoprotein E4 on the Alzheimer amyloid Abeta peptide. Biochemistry. 2001 Dec; 40(49):14995-5001.

63 Pappolla MA, Matsubara E, Vidal R, PachecoQuinto J, Poeggeler B, Zagorski M, et al. Melatonin treatment enhances a $\beta$ lymphatic clearance in a transgenic mouse model of amyloidosis. Curr Alzheimer Res. 2018;15(7): 637-42.

64 O’Neal-Moffitt G, Delic V, Bradshaw PC, Olcese J. Prophylactic melatonin significantly reduces Alzheimer's neuropathology and associated cognitive deficits independent of antioxidant pathways in $\mathrm{A} \beta \mathrm{PP}(\mathrm{swe}) / \mathrm{PS} 1$ mice. Mol Neurodegener. 2015 Jul;10(1):27.

65 Ali T, Kim MO. Melatonin ameliorates amyloid beta-induced memory deficits, tau hyperphosphorylation and neurodegeneration via PI3/Akt/GSk3 $\beta$ pathway in the mouse hippocampus. J Pineal Res. 2015 Aug;59(1):47-59.

66 Hardeland R, Cardinali DP, Brown GM, Pandi-Perumal SR. Melatonin and brain inflammaging. Prog Neurobiol. 2015 Apr;127-128: 46-63.

67 Cardinali DP, Hardeland R. Inflammaging, metabolic syndrome and melatonin: a call for treatment studies. Neuroendocrinology. 2017;104(4):382-97.

68 Carrillo-Vico A, Lardone PI, Alvarez-Sánchez N, Rodríguez-Rodríguez A, Guerrero JM. Melatonin: buffering the immune system. Int J Mol Sci. 2013 Apr;14(4):8638-83.

69 Huether G. Melatonin synthesis in the gastrointestinal tract and the impact of nutritional factors on circulating melatonin. Ann N Y Acad Sci. 1994 May;719 1 The Aging Clo:14658.

70 Bubenik GA, Pang SF. The role of serotonin and melatonin in gastrointestinal physiology: ontogeny, regulation of food intake, and mutual serotonin-melatonin feedback. J Pineal Res. 1994 Mar;16(2):91-9.

71 Bartness TJ, Wade GN. Body weight, food intake and energy regulation in exercising and melatonin-treated Siberian hamsters. Physiol Behav. 1985 Nov;35(5):805-8.

72 Bubenik GA, Pang SF, Hacker RR, Smith PS. Melatonin concentrations in serum and tissues of porcine gastrointestinal tract and their relationship to the intake and passage of food. J Pineal Res. 1996 Nov;21(4):251-6.
73 De Pedro N, Martínez-Alvarez RM, Delgado MJ. Melatonin reduces body weight in goldfish (Carassius auratus): effects on metabolic resources and some feeding regulators. J Pineal Res. 2008 Aug;45(1):32-9.

74 Conde-Sieira M, Librán-Pérez M, López Patiño MA, Soengas JL, Míguez JM. Melatonin treatment alters glucosensing capacity and mRNA expression levels of peptides related to food intake control in rainbow trout hypothalamus. Gen Comp Endocrinol. 2012 Aug; 178(1):131-8.

75 Piccinetti CC, Migliarini B, Olivotto I, Simoniello MP, Giorgini E, Carnevali O. Melatonin and peripheral circuitries: insights on appetite and metabolism in Danio rerio. Zebrafish. 2013 Sep;10(3):275-82.

76 Shaji AV, Kulkarni SK. Evidence of GABAergic modulation in melatonin-induced shortterm memory deficits and food consumption. Methods Find Exp Clin Pharmacol. 1998 May;20(4):311-9.

77 Wolden-Hanson T, Mitton DR, McCants RL, Yellon SM, Wilkinson CW, Matsumoto AM, et al. Daily melatonin administration to middle-aged male rats suppresses body weight intraabdominal adiposity, and plasma leptin and insulin independent of food intake and total body fat. Endocrinology. 2000 Feb 141(2):487-97.

78 Bojková B, Orendás P, Friedmanová L, Kassayová $\mathrm{M}$, Datelinka I, Ahlersová E, et al. Prolonged melatonin administration in 6-monthold Sprague-Dawley rats: metabolic alterations. Acta Physiol Hung. 2008 Mar;95(1): 65-76.

79 Puchalski SS, Green JN, Rasmussen DD. Melatonin effects on metabolism independent of gonad function. Endocrine. 2003 Jul;21(2) 169-73.

80 Génin F, Schilling A, Claustrat B. Melatonin and methimazole mimic short-day-induced fattening in gray mouse lemurs. Physiol Behav. 2003 Sep;79(4-5):553-9.

81 Mustonen AM, Nieminen P, Asikainen J, Saarela S, Kukkonen JV, Hyvärinen H. Continuous melatonin treatment and fasting in the raccoon dog (Nyctereutes procyonoides) - vernal body weight regulation and reproduction. Zool Sci. 2004 Feb;21(2):16372.

82 Le Gouic S, Delagrange P, Atgié C, Nibbelink M, Hanoun N, Casteilla L, et al. Effects of both a melatonin agonist and antagonist on seasonal changes in body mass and energy intake in the garden dormouse. Int J Obes Relat Metab Disord. 1996 Jul;20(7):661-7.

83 Ríos-Lugo MJ, Jiménez-Ortega V, CanoBarquilla P, Mateos PF, Spinedi EJ, Cardinali DP, et al. Melatonin counteracts changes in hypothalamic gene expression of signals regulating feeding behavior in high-fat fed rats. Horm Mol Biol Clin Investig. 2015 Mar;21(3) $175-83$.
Neuroendocrine-Metabolic Dysfunction and Sleep Disturbances in $\mathrm{AD}$
Neuroendocrinology 2019;108:354-364 DOI: $10.1159 / 000494889$ 
84 Singer C, Tractenberg RE, Kaye J, Schafer K, Gamst A, Grundman M, et al.; Alzheimer's Disease Cooperative Study. A multicenter, placebo-controlled trial of melatonin for sleep disturbance in Alzheimer's disease. Sleep. 2003 Nov;26(7):893-901.

85 Brusco LI, Marquez M, Cardinali DP. Melatonin treatment stabilizes chronobiologic and cognitive symptoms in Alzheimer's disease. Neuroendocrinol Lett. 1998;19:111-5.

86 Asayama K, Yamadera H, Ito T, Suzuki H, Kudo Y, Endo S. Double blind study of melatonin effects on the sleep-wake rhythm, cognitive and non-cognitive functions in Alzheimer type dementia. J Nippon Med Sch. 2003 Aug;70(4):334-41.

87 Gauthier S, Reisberg B, Zaudig M, Petersen RC, Ritchie K, Broich K, et al.; International Psychogeriatric Association Expert Conference on mild cognitive impairment. Mild cognitive impairment. Lancet. 2006 Apr; 367(9518):1262-70.

88 Allan CL, Behrman S, Ebmeier KP, Valkanova V. Diagnosing early cognitive declineWhen, how and for whom? Maturitas. 2017 Feb;96:103-8.

89 Cardinali DP, Vigo DE, Olivar N, Vidal MF, Brusco LI. Melatonin therapy in patients with Alzheimer's disease. Antioxidants. 2014 Apr; 3(2):245-77.

90 Cardinali DP, Vigo DE, Olivar N, Vidal MF, Furio AM, Brusco LI. Therapeutic application of melatonin in mild cognitive impairment. Am J Neurodegener Dis. 2012;1(3):280-91.
$91 \mathrm{Wu}$ YH, Feenstra MG, Zhou JN, Liu RY, Toranõ JS, Van Kan HJ, et al. Molecular changes underlying reduced pineal melatonin levels in Alzheimer disease: alterations in preclinical and clinical stages. J Clin Endocrinol Metab. 2003 Dec;88(12):5898-906.

92 Zhou JN, Liu RY, Kamphorst W, Hofman MA, Swaab DF. Early neuropathological Alzheimer's changes in aged individuals are accompanied by decreased cerebrospinal fluid melatonin levels. J Pineal Res. 2003 Sep;35(2): 125-30.

93 Sirin FB, Kumbul Doğuç D, Vural H, Eren I, Inanli I, Sütçü R, et al. Plasma 8-isoPGF2 $\alpha$ and serum melatonin levels in patients with minimal cognitive impairment and Alzheimer disease. Turk J Med Sci. 2015;45(5):1073-7.

94 Xu J, Wang LL, Dammer EB, Li CB, Xu G, Chen SD, et al. Melatonin for sleep disorders and cognition in dementia: a meta-analysis of randomized controlled trials. Am J Alzheimers Dis Other Demen. 2015 Aug;30(5):43947.

95 Zhang W, Chen XY, Su SW, Jia QZ, Ding T, Zhu ZN, et al. Exogenous melatonin for sleep disorders in neurodegenerative diseases: a meta-analysis of randomized clinical trials. Neurol Sci. 2016 Jan;37(1):57-65

96 Furuya M, Miyaoka T, Yasuda H, Wake R, Hashioka S, Miura S, et al. Ramelteon as adjunctive therapy for delirium referred to a consultation-liaison psychiatry service: a retrospective analysis. Int J Geriatr Psychiatry. 2015 Sep;30(9):994-5.
97 Ferracioli-Oda E, Qawasmi A, Bloch MH Meta-analysis: melatonin for the treatment of primary sleep disorders. PLoS One. 2013 May;8(5):e63773.

98 Wilson SJ, Nutt DJ, Alford C, Argyropoulos SV, Baldwin DS, Bateson AN, et al. British Association for Psychopharmacology consensus statement on evidence-based treatment of insomnia, parasomnias and circadian rhythm disorders. J Psychopharmacol. 2010 Nov;24(11):1577-601.

99 Venegas C, García JA, Escames G, Ortiz F, López A, Doerrier C, et al. Extrapineal melatonin: analysis of its subcellular distribution and daily fluctuations. J Pineal Res. 2012 Mar;52(2):217-27.

100 Galley HF, Lowes DA, Allen L, Cameron G, Aucott LS, Webster NR. Melatonin as a potential therapy for sepsis: a phase I dose escalation study and an ex vivo whole blood model under conditions of sepsis. J Pineal Res. 2014 May;56(4):427-38.

101 Andersen LP, Werner MU, Rosenkilde MM, Fenger AQ, Petersen MC, Rosenberg J, et al. Pharmacokinetics of high-dose intravenous melatonin in humans. J Clin Pharmacol. 2016 Mar;56(3):324-9.

102 EFSA Panel on Dietetic Products. Nutrition and Allergies (NDA). Scientific Opinion on the substantiation of a health claim related to melatonin and reduction of sleep onset latency (ID 1698; 1780, 4080) pursuant to Article 13 of Regulation (EC) No 1924/2006. EFSA J. 2011;9:2241. 